\title{
Proceedings of the Third LAN-Transport Workshop
}

Report of the Third Workshop for Local Area Network Implementors of the NBS Specifications of the International Standards Organization Transport Class 4 Protocol - Special Interest Group on File Transfer Protocol

\section{U.S. DEPARTMENT OF COMMERCE}

National Bureau of Standards

Institute for Computer Sciences and Technology

Systems and Network Architecture Division

Washington, DC 20234

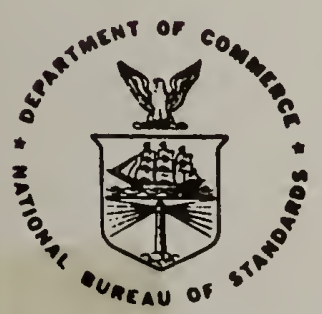

100

.456

U.S. DEPARTMENT OF COMMERCE

$83-2757$ NATIONAL BUREAU OF STANDARDS 
Report of the Third Workshop for Local Area Network Implementors of the NBS Specifications of the International Standards Organization Transport Class 4 Protocol - Special Interest Group on File Transfer Protocol

U.S. DEPARTMENT OF COMMERCE

National Bureau of Standards

Institute for Computer Sciences and Technology

Systems and Network Architecture Division

Washington, DC 20234

July $18-20,1983$ 


\section{CONTENTS}

Abstract

Summary

1. Participants in the Third Workshop

2. Technical Matters

2.1 FTP Presentation and Agreements

2.2 File Management Services: Presentation and Agreements

\subsection{IEEE Statement on Addresses}

3. Administrative Matters

3.1 Fourth Workshop Arrangements

3.2 Participants Indicating Intent to Participate in Demo

3.3 Document Distribution: Tentative Schedule

FTP Service and Protocol Description FTP Formal Description

Write/Create Services and Protocol

File Management

\subsection{Current LAN/Transport Series Mailing List}

Reference

Bibliography 


\section{ABSTRACT}

The National Bureau of Standards' Institute for Computer Sciences and Technology (ICST) has prepared specifications for the International Organization for Standardization's (ISO's) Class 4 Transport Protocol. At the request of a number of companies, ICST organized a workshop series for implementors of these specifications using local area networking technology. The first workshop focused on implementation techniques and strategies so that a multi-vendor demonstration of these protocols can occur at a major computer conference in 1984 - targeted for the NCC 1984. Primarily, the details of CSMA/CD and Transport Class 4 were discussed and parameters were selected. A second workshop focused on token bus LANs and file transfer applications to be run at the targeted 1984 demonstration. This report covers the third in the series of LAN/Transport Workshops, and reports agreements on the specifics of the file transf er protocol.

Keywords: file transfer protocol; communication protocols; computer networks; local area networks.

\section{SUMMARY}

This report documents the third workshop of the LAN/Transport Workshop Series for implementors of the ICST specification of the ISO Class 4 Transport Protocol over IEEE 802 compatible LANs using local area networking technology. Specifically, this report describes the agreements reached by participants concerning the service and protocol of file transfer protocol (FTP). During the second workshop, a subset of the ISO emerging FTP was chosen to operate over transport to provide demonstrable applications. Following the second workshop, NBS prepared a more complete service and protocol description of the selected FTP subset. That document constituted the primary input to the third workshop.

The agreements reached concerning the specification of the FTP subset of service and protocol are documented in the body of this report. A revised service and protocol textual description will be produced and distributed as a result of the third workshop. Differences from the present ISO specification will be clearly marked in that document. They are of two forms. In some instances (for purposes of easing implementations for the projected demonstration) restrictions have been placed upon the ISO specification. The maximum length of file names and their ASCII character composition are examples. In other instances the ISO work has not progressed to the point of defining the protocol in sufficient detail. An example is Protocol Control Information (PCI) encoding. After the forthcoming textual description of the FTP service and protocol, a formal description 
will be prepared and distributed using ISO $\mathrm{SCl}$ /WGl Subgroup B notation.

In addition to work on the FTP, some file management services were presented and discussed. These services, in the form of utilities, will provide the basis for file creation on file server systems for the demonstration. A document describing these utilities will be distributed in the near future.

The participants agreed to the need for a fourth workshop, to be held as earlier planned on October 27 and 28 in Gaithersburg, Maryland. An announcement will be mailed to the current LAN/Transport Workshop Series distribution list in the near future. 


\section{PARTICIPANTS OF THE THIRD WORKSHOP}

The third workshop, chaired by Mr. Maris Graube, Tektronics, was attended by the following.

Ken Aird

Hewlett Packard

3404 E. Harmony Road

Ft. Collins, Colorado 80525

(303) 226-3800

James Berets

Bolt, Beranek, and Newman, Inc.

10 Moulton Street

Cambridge, Massachusetts 02238

(617) 497-2593

Ron Floyd

General Motors

Technical Center MD-66

Warren, Michigan 48090

(313) 575-0877

\section{Atul Garg}

Hewlett Packard

19420 Hom estead Road

Cupertino, Calif ornia 95014

Conrad Geiger

NBI, Inc.

P.O. Box 9001

Boulder, Colorado

(303) 444-5710

Maris Graube

Tektronix

Box 500, MS 50-473

Beaverton, Oregon 97077

(503) 627-1792

John Heafner

National Bureau of Standards

B218/225

Washington, D.C. 20234

(301) $921-3537$

Dittmar Janetzky

Siemens AG

P.O. Box 211080

7500 Karlsfuhe, Germany

(721) 595-2350
Ken Kanaby

General Motors

Technical Center, MD-66

Warren, Michigan 48090

(313) 575-0899

Chak Lai

Digital Equipment Corporation

21333 Haggerty

Novi, Michigan 48050

(313) $348-8900$

Andy Luque

Tektronix, Inc.

P.O. Box 500, MS 92-803

Beaverton, Oregon 97062

(503) 629-1343

Joseph R. Maixner

Associated Computer Consultants

2901 Park Avenue

Soquel, Calif ornia 95073

(408) 425-0937

June Nishimoto

Hewlett-Packard/IND

246 Edlee Avenue

Palo Alto, California 94306

(415) 494-0652

James Quigley

IBM-GPD

1501 California A venue

Palo Alto, Calif ornia 94304

Allen B. Rochkind

Intel Corporation

3065 Bowers A venue

Santa Clara, California 95051

(408) 987-7817

Douglas B. Smith

University of Michigan

and Industrial Technology, Inst.

Ann Arbor, Michigan 48109

(313) 763-0588 
Perry Taylor

IBM Branch Office 129

18000 West Nine Mile Road

Southfield, Michigan 48075

Roger Thompson

IBM

1501 California Avenue

Palo Alto, Calif ornia 94304

(415) 855-7235

Mike Wolf ersperger

Sperry Univac

P.O. Box 500

Blue Bell, Pennsylvania 19424

(215) 542-4313 


\section{TECHNICAL MATTERS}

\subsection{FTP Presentation and Agreements}

An outcome of the second workshop was the selection of a file transfer protocol to support applications for the demonstration. NBS agreed to prepare a document for the third workshop discussions, based upon the emerging ISO work on FTP. The document was to further define a subset of the ISO FTP service and protocol. This document was prepared by Bolt, Beranek, and Newman, Inc. under contract to NBS, and was presented by Mr. James Berets of BBN.

Agreements reached by the participants with respect to this document follow.

\subsubsection{File Length}

The maximum file length will be $64 \mathrm{~K}$ octets. Larger sizes are permitted only by mutual agreement between/among participants desiring to demonstrate bulk data transfer applications.

\subsubsection{File Data End (FDE) Request}

Three proposals were offered and discussed:

1. Permit combining all or the remaining portion of the data to be transmitted with the FDE. That is, allow "piggybacking" of data PDUs with the FDE PDU.

2. Replace the FDE PDU by an EOT bit in the data PDU as done in Transport.

3. Send the FDE as a separate PDU after all data PDUs have been transmitted. This corresponds to present ISO documentation.

It was decided to support the third proposal, corresponding to the ISO method.

\subsubsection{Interpretation of Even Length Protocol Control Information (PCI)}

For lower layer protocols it is desirable to insure an even length header (protocol control information) to assist DMA transfers. Several proposals were discussed.

1. The length of the total PDU would be an even number of octets. The end of the header would be padded (if necessary) to achieve an even octet count.

2. Each of the header and the data portions of the PDU would be an even number of octets. Padding would be applied at the end of each as necessary.

Both proposals were rejected. The FTP will not concern itself with whether or not the PDU length is even or odd. 


\subsubsection{F-Abort Request Diagnostic}

It was noted that the Request did not carry a diagnostic field whereas the Indication did permit a diagnostic message to the user of FTP. This is consistent with the ISO specification and was thus left as is. It was noted that the FTP issuing an F-Abort.Indication could specify whether the abort was caused by the network service or initiated by the peer FTP.

\subsubsection{F-Transfer End}

It was noted that in the NBS input document[1] the F-Transfer End state appeared to be superfluous. It was decided to leave the state (consistent with the ISO specification). Although the state is not logically necessary for the subset of FTP chosen for the demo, it would be logically required for a complete implementation of the ISO FTP.

\subsubsection{Maximum PDU Size for Peer FTPs}

There shall be no restriction on length of PDUs other than that required by file length. See section 2.1.l.

\subsubsection{Write/Create}

The possibility of including write and create services for the demo was discussed during the second workshop. A decision was postponed until further discussion at the third workshop. From the discussion during the third workshop it was evident that some participants felt that the write/create should be included in order to lend more credence to the demo. Others felt that schedules did not permit the inclusion of write/create. The following decisions were reached: 1)the prose description of FTP service and protocol will be revised and distributed; 2) the formal description (subgroup B notation) of the protocol will be produced and distributed; and 3) write/create will be described in a separate prose document. If it can be prepared before the fourth workshop in October, then it will be reintroduced for discussion at that time.

\subsubsection{Interpretation of ASCII String}

The following agreements were reached with respect to files and file contents.

1. In general, there is a need for all 256 characters.

2. For text files a CR should be followed by an LF.

3. Text file applications should expect lower case characters from the network and should convert to upper case if terminal requirements dictate.

4. File names will be a maximum of eight characters in length; the first character will be alphabetic.

The only characters permissible in the file name are: upper case A through $\mathrm{Z}$ and 0 through 9 . The file name used in the select service primitive will be identical to the name returned; that is, no suffixes 
such as generation or version will be appended to the file name appearing in the select.

5. Admitted file types will be:

i) text,
ii) NAPLPS graphics,
iii) 3270 ,
iv) binary data,
v) variable length record of ASCII characters; each read request
obtains a separate logical record, and
vi) Regis graphics.

6. Participants will supply a hardcopy list of all files provided. The file type (see 5 above) will be indicated.

7. Any unrecognizable file name will be treated as a text file.

8. The data field of the FDR will be structured as: one octet specifying data type, followed by the data.

\subsubsection{Protocol Errors}

Upon receiving an error notification from the peer FTP or upon receiving an error notification from the transport protocol, the FTP will abort. User signalled errors are treated in any way the implementor decides.

\subsubsection{User Diagnostics}

Reasonable ASCII strings denoting common errors will be documented in the revised prose description of the service and protocol. These strings will be supplied by the document editor and will be reviewed at the fourth workshop.

\subsubsection{PDU Format and Encoding}

It was decided to follow the format and encoding style used in transport, session, and internetwork. This includes a fixed portion of the header, beginning with two octets of length followed by one octet of PDU type. Following the fixed portion of the header, there may appear a variable portion of the header. Optional header parameters will be encoded using Header Item Coding (HIC). The data portion of the PDU follows the header. The exact format and encoding for each PDU type will appear in the revised prose description of the FTP service and protocol.

It was noted that ISO has not defined the PDU formats and that ANSI has only recently begun to address this problem. The initial ANSI work on FTP PDU formats differs from that of Layers 3, 4, and 5. Participants of the LAN/Transport workshops will alert ANSI to the formatting decisions made for purposes of the demonstration. 


\subsubsection{Addressing}

1. There will be a one-to-one mapping of FTP connections onto Transport connections.

2. A system-wide convention was accepted such that the called address will be eight characters in length. A list will be published for each endsystem. The called address translates into a transport address (which is composed of a prefix and a network address).

3. A determination of whether or not the called and calling fields are required or optional in the FCR PDU will be made. If required (according to ISO), then a null address (i.e., value of the length field equal zero) will be used. If optional, then they will be omitted. Called and calling addresses will adhere to the same encoding and conventions accepted for file names. See section 2.1 .8 , item 4 above.

\subsubsection{Octet Ordering in Multi-Octet Fields}

In multi-octet fields, such as the 2-octet length field, the least significant octet appears first and the most significant octet appears last. Ordering was debated and the participants were evenly divided in their opinions. It is noted that the decision reached is consistent with multi-octet encoding in Transport PCI. It was further agreed that, should ISO choose a different ordering, that the LAN Transport workshop participants would change accordingly.

\subsubsection{Concatenation of PDUs}

It was decided that FTP PDUs would not be concatenated as a single TSDU.

\subsubsection{Data Discard}

It was decided that upon abort, cancel, or T-disconnect, that data received would be discarded.

\subsection{File Management Services: Presentation and Agreements}

Mr. Allen Rochkind presented a proposal for voluntary implementation of a set of utilities for file server and user. These utilities provide the basis for file installation on file server systems and provide for the display of file directory contents. A document describing this proposal, which was accepted by the participants, will be produced by Mr. Rochkind and distributed by NBS.

\subsection{IEEE Statement on Addresses}

The IEEE 802 committee met the week of July 11. The proposal (by LAN/Transport participants) for the IEEE to assign the LSAP as 01000001 for this demonstration was discussed. The value chosen by the IEEE was 01111111. 


\section{ADMINISTRATIVE MATTERS}

\subsection{Fourth Workshop Arrangements}

The participants agreed to the need for a fourth workshop, to be held on October 27 and 28 at the Marriott Hotel in Gaithersburg, Maryland. Announcements will appear in the Federal Register and will be mailed to the current participant list (see section 3.4) of the LAN/Transport Workshop Series.

\subsection{Participants Indicating Intent to Participate in Demo}

The participants asked that the list of organizations intending to participate in the demonstration be listed in these minutes. Af ter August 15, the deadline established by NBS for companies to make commitments, the participants will be notified of those intending to participate in the demonstration.

\subsection{Document Distribution: Tentative Schedule}

\subsubsection{FTP Service and Protocol Description}

A revised version of the input document to the third workshop will be produced and distributed about the first of September.

\subsubsection{FTP Formal Description}

The protocol as described in the above referenced prose document will be specified using the subgroup B notation of TC97/SCl6-WGl. This specification should be available about the middle of September.

\subsubsection{Write/Create Service and Protocol}

Following development of the above documents, a prose description of the write and create services and protocol will be specified. This document may contain only those services/protocol, or it may be specified as an extension of the document referenced in 3.3.1, but under separate cover. It is hoped that this document can be made available for discussion at the fourth workshop.

\subsubsection{File Management}

Intel will produce a document describing optional file management services. (See section 2.2.) This document will be distributed by NBS upon receipt from Mr. Rochkind. 
3.4 Current LAN/Transport Series Mailing List

Able Computer

Edward Efron

1732 Reynolds Avenue

Irvine, California 92714

Allen-Bradley Company

E. Delahostria

747 Alpha Drive

Highland Heights, Ohio 44143

Bob Jones

747 Alpha Drive

Highland Heights, Ohio 44143

David C. Sweeton

747 Alpha Drive

Highland Heights, Ohio 44143

American Bell

A. A. Akiwpelu

307 Middletown/Lincrof t Road

Lincroft, New Jersey 07738

Michael Herrick

307 Middletown/Lincroft Road

Lincroft, New Jersey 07738

Associated Computer Consultants

Joseph Maixner

Local Area Network Center

2901 Park A venue

Sequel, California 95073
BDM Corporation

John Long

International Support

7915 Jones Branch Drive

McLean, Virginia 22102

Roger S. Novack

7915 Jones Branch Drive

McLean, Virginia 22102

Boeing Computer Services Company

Sheldon Blauman

P.O. Box 24346

Seattle, Washing ton 98124

Chr is Dunlap

7980-90 Gallows Road

Vienna, Virginia 22180

Bolt, Beranek, \& Newman

James Berets

10 Moulton Street

Cambridge, Massachussetts 02238

John Burruss

50 Moulton Street

Cambridge, Massachussetts 02238

Ross Callon

50 Moulton Street

Cambridge, Massachusetts 02238 
Burroughs Corporation

Scott A. Stein CNG/Tredyffrin Plan

P.O. Box 203

Paoli, Pennsylvania 19301

Contel Information Systems

Samuel E. Clopper, Jr.

Government Systems Division

11781 Lee Jackson Highway

Fairfax, Virginia 22033

Concord Data Systems

Ross Seider

303 Bear Hill Road

Wal tham, Massachusetts 02154

Control Data Corporation

J. L. Nading

4201 N. Lexington A venue

Arden Hills, Minnesota 55112

B. S. Sekhon

4201 N. Lexington Avenue

Arden Hills, Minnesota 55112

3 Com Corporation

Pamela Lawson

1390 Shorebird Way

Mountain View, California 94043

Greg Shaw

1390 Shorebird Way

Mountain View, California 94043

Digital Equipment Corporation

Chak Lai

21333 Haggerty Road

Novi, Michigan 48050

Anthony G. Lauck

1925 Andover Street

'Tewksbury, Massachusetts 01876

Jeff Schriesheim

1925 Andover Street

Tewksbury, Massachusetts 01876
E-Systems

Marvin Jenkel

7700 Arling ton Blvd.

Falls Church, Virginia 22046

William Livingston

7700 Arlington Blvd.

Falls Church, Virginia 22046

William Miller

7700 Arling ton Blvd.

Falls Church, Virginia 22046

Federal Bureau of Investigation

Jerry Smith

Room 8391, TL-245

10 th \& Pennsylvania A venue, NW

Washing ton, D. C. 20535

Fisher Body

Charles D. Groff

30001 Van Dyke Avenue

Warrent, Michigan 48090

Ford Motor Company

Richard Batty

Room 890 WHQ

The American Road

Dearbord, Michigan 48121-1899

Shaun Devlin

Room S-2097, Scientific Research Lab

P.O. Box 2053

Dearborn, Michigan 48121-1899

Melvin Gable

Room E-ll74, Scientific Research Lab

P.O. Box 2053

Dearborn, Michigan 48121-1899

General Motors Corporation

Ronald Floyd

GM ME\&D-MD/66

GM Technical Center

Warren, Michigan 48090-9040

Ken Kanaby

Technical Center, MD-66

Warren, Michigan 48090-9040 


\section{Mike Kaminski}

Manufacturing Development

Technical Center

Warren, Michigan 48090-9040

Dale F. Larson

GM Technical Center

12 MI\&MOUND-N2-GMECC

Warren, Michigan 48080-9040

Gould, Inc.

Rao Cherukuri

6901 Sunrise Blvd.

Ft. Lauderdale, Florida 33310

Hewlett Packard

Ken Aird

3404 E. Harmony Road

Ft. Collins, Colorado 80525

Atul Garg

19420 Homestead Road

Cupertino, California 95014

June Nishimoto

246 Edlee Avenue

Palo Alto, California 94306

Honeywell Information Systems

William Stallings

7900 Westpark Drive

McLean, Virginia 22102

IBM Corporation

G. A. Deaton, Jr.

IBM Communications Products Division

E87/651

P.O. Box 12195

Research Triangle Park, North Carolina 27709

J. J. Quigley

IBM Systems Products Division

$24 \mathrm{E} / 037$

P.O. Box 10500

Palo Alto, California 94304

Pat Mulvey

24V B231-l

P.O. Box 1328

Boca Raton, Florida
Perry Taylor

2747 Franklin Road

Bloomfield Hills, Michigan 48013

Roger Thompson

1501 Calif ornia Avenue

Palo Alto, California 94304

ICL

J. R. Cadwallader

West Avenue

Kidsgrove

Stoke-on-Trent ST7 1TL

United Kingdom

John Salter

West Avenue

Kidsgrove

Stoke-on-Trent ST7 ITL

United Kingdom

K. J. Turner

West Avenue

Kidsgrove

Stoke-on-Trent ST7 1TL

Inco. Inc.

Paul Styger

C3I Systems Division

8260 Greensboro Drive

McLean, Virginia 22102

Thomas Trump

C3I Systems Division

8260 Greensboro Drive

McLean,Virginia 22102

Industrial Technology Institute

P. David Fisher

2901 Baxter Road

Ann Arbor, Michigan 48109

Integrated Microcomputer Systems, Inc.

Kenneth Lindsay

1235 Jefferson Davis Highway

Suite 1408

Arlington, Virginia 22202

Howell Mei

1235 Jeff erson Davis Highway

Suite 1408

Arington, Virginia 22202 
Intel Corporation

Allen Rochkind

SC6-056

3200 Lakeside Drive

Santa Clara, California 95051

INTERLAN, Inc.

David Potter

3 Lyberty Way

Westford, Massachusetts 01886

Jonathan Taylor

3 Lyberty Way

Westford, Massachusetts 01886

Los Alamos National Laboratory

Don Tolmie

Los Alamos, New Mexico 87545

Mitre Corporation

Paul J. Brusil

P.O. Box 208

Bedford, Massachusetts 01730

David Oppenheim

P.O. Box 208

Bedford, Massachusetts 01730

Motorola

Bruce Loyer

P.O. Box 2953

Phoenix, Arizona 85062

NBI, Inc.

Douglas McCallum

P.O. Box 9001

Boulder, Color ado 80301

Conrad Geiger

P.O. Box 9001

Boulder, Colorado 80301

National Bureau of Standards

Robert Blanc

Institute for Computer

Sciences \& Technology

Room A231, Building 225

Washington, D. C. 20234
Dennis Branstad

Institute for Computer

Sciences \& Technology

Room A219, Building 225

Washington, D. C. 20234

Robert Carpenter

Institute for Computer

Sciences \& Technology

Room A219, Building 225

Washington, D. C. 20234

John Heafner

Institute for Computer

Sciences \& Technology

Room B218, Building 225

Washing ton, D. C. 20234

Jerry Linn

Institute for Computer

Sciences \& Technology

Room B212, Building 225

Washington, D. C. 20234

William Majurski

Institute for Computer

Sciences \& Technology

Room A219, Building 225

Washington, D. C. 20234

Kevin Mills

Institute for Computer

Sciences \& Technology

Room B212, Building 225

Washington, D. C. 20234

James Moulton

Institute for Computer

Sciences \& Technology

Room B212, Building 225

Washington, D. C. 20234

Robert Rosenthal

Institute for Computer

Sciences \& Technology

Room B226, Building 225

Washing ton, D. C. 20234

Shirley Watkins

Institute for Computer

Sciences \& Technology

Room B226, Building 225

Washington, D. C. 20234 


\section{NCR Comten}

David W. Tillman

2700 Snelling Avenue North

St. Paul, Minnesota 55113

North Carolina State University

Bill Bhimiak

School of Physical and Mathematic

Sciences \& School of Engineering

Box 5490

Raliegh, North Carolina 27650

Phillips Inf ormation Systems

Rene Archambault

5250 Ferrier

Montreal, Canada H4BlL4

Seimens AG

Dittmar Janetzky

P.O. Box 211080

7500 Karlsfuhe, Germany

Solosystems

Der-Hwa Gan

670 Gail Avenue \#E-27

Sunnyvale, California 94086

Source Telecomputing

Leslie Spira

1616 Anderson Road

McLean, Virginia

Sperry Univac

Jim McNulty

P.O. Box 500

Blue Bell, Pennsylvania 19124

Mike Wolf ersperger

P.O. Box 500

Blue Bell, Pennsylvania 19124
Sytek, Inc.

William C. Taylor 6000 Executive Blvd. Suite 205A

Rockville, Maryland 20852

Systems Architects, Inc.

Ashok Kuthyar

510 W. Annandale Road

Falls Church, Virginia 22046

Tektronix, Inc.

Maris Graube

P.O. Box 500

Beaverton, Oregon 97077

Andy Luque

P.O. Box 500

Beaverton, Oregon 97077

University of Michigan \& Industrial Technology Institute

Douglas B. Smith

Ann Arbor, Michigan 48109

Ungerman-Bass

John M. Davidson

2560 Mission College Blvd.

Santa Clara, CA 95050

Xerox Corporation

Juan Bulnes

OPD Office Systems Business Unit

3450 Hillview Avenue

Palo Alto, California 94304 


\section{REFERENCE}

[1] "Multi-Vendor Demonstration File Transfer Protocol," NBS, B218, Technology Building, Washington, D. C. 20234. 


\section{BIBLIOGRAPHY}

Proceedings of the First LAN-Transport Workshop, NBSIR 83-2673, National Bureau of Standards, Washington, D. C., February l-2, 1983.

Proceedings of the Second LAN-Transport Workshop, NBSIR 83-2717, National Bureau of Standards, Washington, D. C., May 5-6, 1983. 
NBS-114A (REV, 2.8C)

U.S. DEPT. OF COMM.

1. PUBLICATION OR

2. Performing Organ. Report Nof 3. Publication Date

BIBLIOGRAPHIC DATA

SHEET (See instructions) REPORT NO.

NBSIR $83-2757$

July 1983

4. TITLE AND SUBTITLE

Proceedings of the Third LAN-Transport Workshop

5. AUTHOR(S)

6. PERFORMING ORGANIZATION (If joint or other than NBS, see instructions)

7. Contract Grant No.

NATIONAL BUREAU OF STANDARDS

DEPARTMENT OF COMMERCE

WASHINGTON, D.C. 20234

8. Type of Report \& Period Covered

9. 5POASORING ORGAINIZATION NAME AND COMPLETE ADORESS (Street, City, Stute, ZIP)

Institute for Computer Sciences and Technology

National Bureau of Standards

U.S. Deaprtment of Commerce

Washington, DC 20234

10. SUPPLEMENTARY NOTES

Document describes a computer program; SF-185, FIPS Software Summary, is attached.

11. ABSTRACT (A 200-word or less foctual summary of most significant information. If document includes a significant bibliography or literature survey, mention it here)

The National Bureau of Standards' Institute for Computer Sciences and Technology (ICST) has prepared specifications for the International Organization for Standardization's (ISO) Class 4 Transport Protocol. At the request of a number of companies, ICST organized a workshop series for local area network implementors of these specifications. The first workshop focused on implementation techniques and strategies so that a multivendor demonstration of these protocols can occur at a major conference in 1984--targeted for the NCC 1984. Primarily, the details of CSMA/CD and Transport Class 4 were discussed and parameters were selected. A second workshop focused on token bus LANs and file transfer application to be run at the targeted 1984 demonstration. This report covers the third in the series of LAN/Transport Workshops, and reports agreements on the specifics of the transfer protocol.

12. KEY WORDS (Six to twelve entries: alphabetical order; capitalize only proper names; and separate key words by semicolons)

file transfer protocol; communication protocols; computer networks; local area networks

13. AVAILABILITY

[X] Unlimited

$\square$ For Official Distribution. Do Not Release to NTIS

$\square$ Order From Superintendent of Documents, U.S. Government Printing Office, Washington, D.C. 20402.

14. NO. OF

PRINTED PAGES

[X] Order From National Technical Information Service (NTIS), Springfield, VA. 22161

19

15. Price 
